\title{
Doctor, are you healthy? A cross-sectional investigation of oncologist burnout, depression, and anxiety and an investigation of their associated factors
}

\author{
Carlos Eduardo Paiva ${ }^{1,2,4^{*}}$ (D), Beatriz Parreira Martins ${ }^{3}$ and Bianca Sakamoto Ribeiro Paiva ${ }^{1,2}$
}

\begin{abstract}
Purpose: Doctors who work at cancer hospitals are at high risk of developing emotional distress. This study evaluated the prevalence of burnout, anxiety, and depression in a sample of oncologists of various specialties and sought to identify how much of this distress is explained by specific pre-established characteristics.

Methods: This cross-sectional study used online surveys. Burnout was measured using the Maslach Burnout Inventory $(\mathrm{MBI})$, and anxiety and depression were measured using the Hospital Anxiety and Depression Scale (HADS). The variables associated with $p$-values $<0.10$ in the univariate analyses were included in blocks of hierarchical binary logistic regression models to identify the predictors of burnout, depression, and anxiety.

Results: Of the 227 physicians (response rate $=70.5 \%), 132(58.1 \%)$ were identified as having burnout (high emotional exhaustion [EE] and depersonalization [DP]); furthermore, 28 (12.3\%) had depression (HADS-D $\geq 11$ ), and 44 (19.4\%) had anxiety (HADS-A $\geq 11$ ). The block of perceptions related to the workplace explained $22.4 \%, 7.7 \%$, and $10.6 \%$ of the variances of burnout, depression, and anxiety, respectively. On the other hand, the outside-of-work characteristics block explained only $3.1 \%, 13.4 \%$, and $3.4 \%$ of the variances of burnout, depression, and anxiety, respectively.

Conclusions: Work-related stressors are associated with burnout, but few are associated with anxiety and depression. Outside-of-work characteristics explained little of the distress reported by physicians. Strategies focused on perceptions of professional recognition and lower workloads that stimulate positive relationships between doctors and other health professionals are desirable in oncological context.
\end{abstract}

Keywords: Cancer, Depression, Anxiety, epidemiology, quality of life

\section{Background}

The high mortality and distress related to cancer, coupled with the increasing number of patients with cancer [1-3], places physicians who care for these patients at high risk for distress, i.e., anxiety, depression, and (in particular) burnout [4].

Burnout is a multifactorial syndrome characterized by physical and emotional exhaustion (EE), primarily catalyzed by professional demands. Burnout is characterized

\footnotetext{
* Correspondence: drcarlosnap@gmail.com

${ }^{1}$ Department of Clinical Oncology, Barretos Cancer Hospital, Barretos, São Paulo, Brazil

${ }^{2}$ Health-Related Quality of Life Research Group (GPQual), Learning and Research Institute, Barretos Cancer Hospital, Barretos, São Paulo, Brazil Full list of author information is available at the end of the article
}

by high levels of EE, cynicism and depersonalization (DP; i.e., detachment or disengagement), and a decreased perception of personal fulfillment (PF) [5]. Burnout interferes with perceptions of personal well-being, increasing the risks of suicidal ideation, absenteeism, and lower medical productivity [6, 7]. Numerous studies have been published evaluating depression in medical students, interns, residents, and fellows [8-10]; however, the literature on depression and anxiety among oncologists is scarce.

Modern doctors must cope with potential stressors such as increasing government regulations of their professional activities, processes for errors/improper medical practices, briefer patient time, increased clinical demands, the commercial aspects of medicine, and the 
continuous expansion of scientific knowledge [11]. A high burden exists among oncologists regarding the frustration of treating patients with an incurable disease who are often distressed, in many cases angered by the situation, and experience physical-psychological-social-existential suffering. Oncologists often stand in the midst of this emotional conflict, trying to mediate between the cancer and the suffering patient.

This study sought to evaluate the prevalence of burnout, anxiety, and depression in a sample of physicians dedicated to oncology of various specialties and to identify how much of this distress could be explained by personal characteristics, those related specifically to the workplace, stressors related to work perceived by physicians, and extra-professional characteristics.

\section{Methods}

\section{Place of study}

The Barretos Cancer Hospital (BCH) is located in Barretos - SP (Brazil), a city with approximately 110,000 inhabitants. It is currently one of the largest cancer hospitals in Brazil, providing free care for 10,000 new cancer cases annually. $\mathrm{BCH}$ is an assistential, teaching, and research institution.

\section{Ethical aspects}

The Research Ethics Committee of HCB approved the study protocol (CEP/HCB no. 1.091.484/2015). Participants indicated their agreement to participate in the study via the electronic informed consent included in the survey form.

\section{Study design}

A cross-sectional study design with online surveys was employed.

\section{Casuistry}

During the research period, 323 physicians (i.e., staff, residents, and fellows) worked in the hospital and were invited to participate in the study.

\section{Calculation of sample size}

Estimates suggest that approximately $60 \%$ of the population of physicians who work in hospitals present with burnout $[12,13]$. Accepting an estimate of absolute precision (i.e., how close the estimate is to the true value) of $10 \%$ and a level of significance of $1 \%$, the minimum estimated sample size was 160 physicians [14].

\section{Assessment instruments}

Sociodemographic data and variables related to the work and daily lives of physicians were included in the survey.

\section{Maslach burnout inventory (MBI)}

The MBI is composed of 22 questions answered using a seven-point Likert scale ranging from 0 (never) to 6 (every day). Of the 22 questions, nine evaluated EE, five evaluated DP, and eight evaluated PF. The classification for each dimension is given by the sum of their respective affirmations, making it possible to highlight them in low, moderate, or high levels. The PF dimension was reverse scored $[15,16]$. The following cutoff values were used: EE (low level, $\leq 18$; intermediate level, 19-26; high level, $\geq 27$ ); DP (low level, $\leq 5$; intermediate level, 6-9; high level, $\geq 10$ ); and PF (low level, $\geq 40$; intermediate level 39-34; high level $\leq 33$ ). Burnout was diagnosed when high levels of EE, DP, or both were found [17]. We paid for the rights to use the MBI, and its use was duly authorized (Mind Garden, Inc., http://www.mindgarden.com/).

\section{Hospital anxiety and depression scale (HADS)}

The HADS [18] is composed of seven items related to anxiety symptoms and seven related to the depression symptoms, totaling 14 items. All of the items are answered using a four-point Likert scale. For each dimension (anxiety/depression), cut-off scores are established for "possible cases" or "probable cases". These scores are calculated based on the sum of the questions used to evaluate the anxiety and depression domains. In this study, scores $\geq 11$ were considered positive for both the anxiety and depression domains.

\section{Questionnaire developed for the present study}

The physician characteristics potentially related to burnout, anxiety, and depression were included in a questionnaire developed specifically for the present study. This questionnaire was created after meetings among the authors and a review of the literature. These characteristics were grouped into four main categories: (1) personal characteristics of physicians that are innate or difficult to modify; (2) physical or objective workplace characteristics; (3) the work-related stressors perceived by physicians; and (4) outside-of-work characteristics such as leisure, religiosity/spirituality, physical activity, and family relationships (Additional file 1). Content validation was conducted with 10 physicians from different departments using cognitive debriefing and think-aloud method. All the questions were adequately understood. Two items were modified after suggestions; both suggestions were to include examples between parenthesis (regarding leisure and physical activity). An Expert Committee was formed to analyze the development of the questionnaire and the results of the pilot testing. In addition to the authors of the study, the committee was composed of one physician (MD, PhD), two experts in questionnaire validation and a psychologist. They 
analyzed all responses and considered the questionnaire valid to be used in the present survey. The translated English version of the questionnaire is shown in Additional file 2.

\section{Data collection}

To apply the instruments, the web-based program SurveyMonkey (https://pt.surveymonkey.com) was used. The doctors received an e-mail explaining the research and a link that provided access to the informed consent and the survey. They received three reminder e-mails about the survey each week for 3 weeks. Unanswered e-mails were considered refusal to participate.

\section{Statistical analyses}

Variables were individually compared based on diagnoses of burnout (yes/no), depression (yes/no), and anxiety (yes/no). Categorical and continuous variables were analyzed using Fisher's exact test and Mann-Whitney U test, respectively. Variables associated with $p<0.10$ in the univariate analyses were included in blocks in a hierarchical binary logistic regression model to identify the predictors of burnout, depression, and anxiety. The blocks were divided a priori into (1) personal characteristics of the physicians; (2) workplace characteristics; (3) workplace-related stressors perceived by the physicians; and (4) outside-of-work characteristics. The difference in the measurement of error $(-2 \log$ likelihood) between different blocks is the block $\chi^{2}$. Statistical tests for the estimated models (model $\chi^{2}$ ) and block within each model were described. In addition, we assessed the amount of variance (\%) explained by the logistic models using Nagelkerke's $\mathrm{R}^{2}$ parameter [19]. A two-tailed $p$-value of $<0.05$ was considered significant. All statistical analyses were conducted using SPSS for Windows version 21 (SPSS, Inc., Chicago, IL, USA).

\section{Results}

\section{Population description}

A total of 323 physicians were invited to participate in this study; 237 accessed the research link, and four chose not to participate after reading the electronic informed consent. Of the 233 responders, the data for seven were not analyzed because those doctors did not complete at least the MBI. Thus, the final sample was composed of 227 physicians (response rate $=70.5 \%$ ). A CONSORT flow diagram is described in Additional file 3.

The median age of the physicians was 34 years old (25th percentile [p25]-p75 $=30-40$ years old). Most physicians $(n=123,54.2 \%)$ received more than BRL 20,000 annually, were married $(n=140,61.7 \%)$, and had no children $(n=130,57.3 \%)$. A total of $139(61.2 \%)$ were staff members, and 88 (38.8\%) were residents or fellows. In total, $88(38.8 \%)$ were clinicians, $63(27.8 \%)$ were surgeons, 57 (25.1\%) worked in the diagnostic sector, 11 (4.5\%) were emergency or Intensive Care Unit (ICU) physicians, and eight (3.5\%) were anesthesiologists (Additional file 4).

\section{Burnout, depression, and anxiety scores and prevalence}

In total, $132(58.1 \%, 95 \% \mathrm{CIs}=51.5-64.3 \%)$ physicians were identified as having burnout (i.e., EE, high DP, or both), $28(12.3 \%, 95 \%$ CIs $=8.0-17.2 \%)$ had depression (HADS-D $\geq 11)$, and $44(19.4 \%, 95 \%$ CIs $=14.6-24.8 \%)$ had anxiety (HADS-A $\geq 11$ ). Regarding the MBI domains, 95 (41.9\%, 95\% CIs = 35.4-48.7\%), 85 (37.6\%, 95\% CIs $=31.0-44.2 \%)$, and $115 \quad(50.9 \%, 95 \%$ CIs $=44.2-$ $57.1 \%)$ physicians were considered as having high $\mathrm{EE}$, high DP, and low PF, respectively (Fig. 1).

The physicians were further categorized according to the median time of practice in the hospital $(\leq 2$ years vs. $>2$ years). Physicians with less than 2 years of practice in the hospital presented a higher number of burnout compared to physicians with longer practice times (64.6\% vs. $51.3 \%, p=0.045)$. When analyzed by the burnout domain scores, an statistical significant difference was observed only in relation to $E E(\leq 2$ years, high $\mathrm{EE}=49.1 \%$ vs. $>2$ years, high $\mathrm{EE}=34.2 \%, p=0.012$ ). Additional file 4: Table S2 describes the analysis of burnout in function of years of practice in the present hospital.

\section{Multivariate analyses}

All variables with $p$-values $<0.10$ in the univariate analyses (Table 1) were included in hierarchical binary logistic regression models for each analyzed outcome. The variables were included in blocks according to an a priori defined model. The final burnout regression model explained $43.6 \%$ of the total variance; blocks 1,2 , 3 , and 4 individually explained $10.5 \%, 7.6 \%, 22.4 \%$, and $3.1 \%$, respectively. The chance of being diagnosed with burnout was higher among physicians who reported being pessimistic $(\mathrm{OR}=7.601, p=0.036)$, working in ICU/ emergency department [ED] (OR $=6.456, p=0.063)$, perceiving a lack of hospital recognition $(\mathrm{OR}=2.605, p=$ $0.018)$, and excess work $(\mathrm{OR}=4.735, p<0.001)$. On the other hand, physicians who reported a higher frequency of leisure activities were less likely to be diagnosed with burnout (moderate: $\mathrm{OR}=0.321, p=0.009$; frequent/very frequent: $\mathrm{OR}=0.362, p=0.065$; Table 2 ).

The final depression regression model explained 58.4\% of the total variance; blocks $1,2,3$, and 4 individually explained $25.2 \%, 12.1 \%, 7.7 \%$, and $13.4 \%$, respectively. Physicians who reported being pessimistic were approximately 10 times more likely to have depression than those who reported being optimistic (OR $=10.729, p=$ 0.021). Physicians who practiced regular physical activity more than twice per week were less depressed $(\mathrm{OR}=$ 

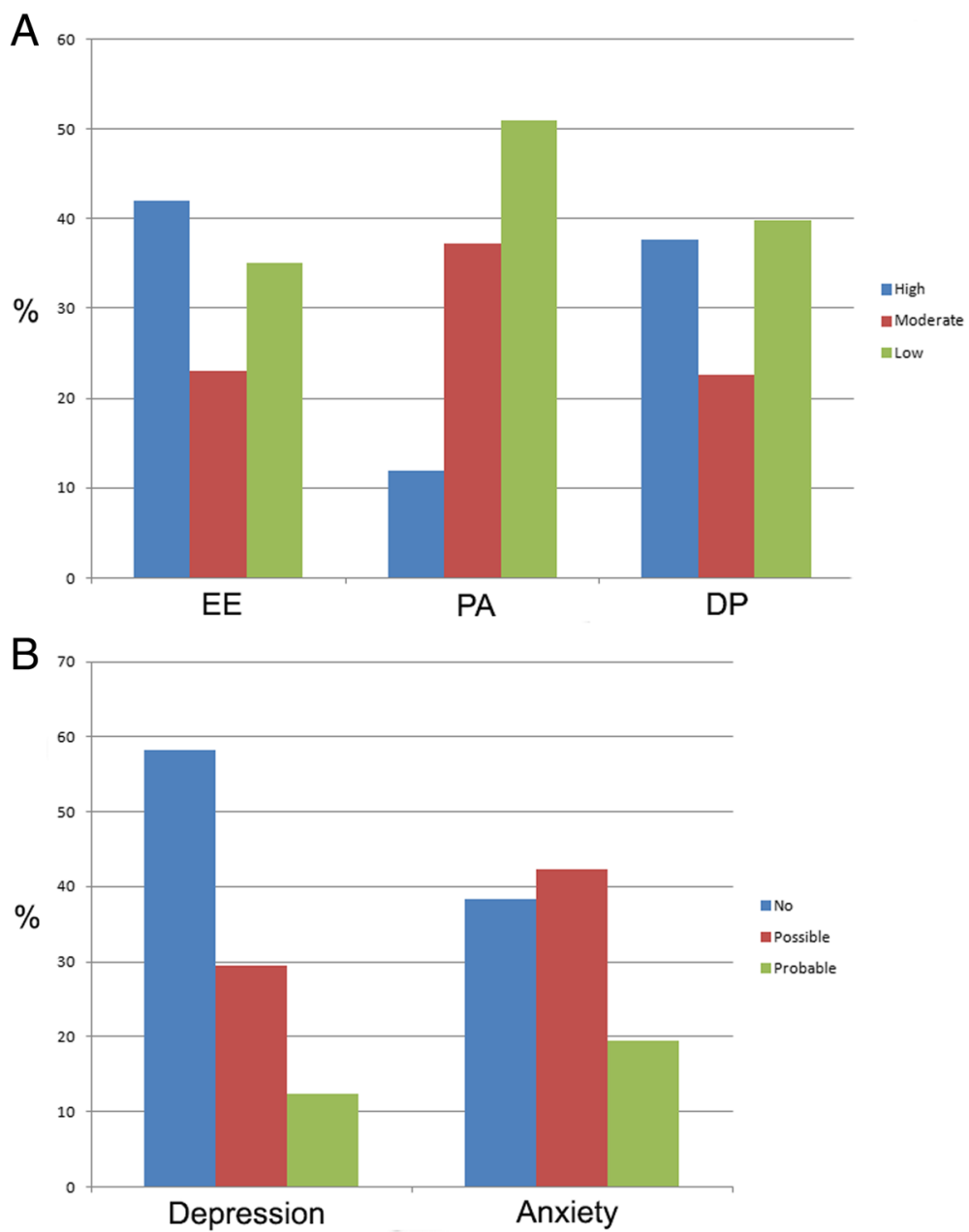

Fig. 1 Prevalence rates (\%) of burnout, depression and anxiety among physicians from a cancer hospital. a Burnout domains. EE: emotional exhaustion; PA: personal accomplishment; DP: depersonalization. Scores of MBI are represented in columns printed in different colors: blue, high levels; red, moderate levels; green, low levels. b Scores of HADS-D (depression) and HADS-A (anxiety) are divided in three categories: no $(<8$, blue), possible $(8-11$, red), and probable (>11, green) depression/anxiety

$0.049, p=0.006)$ than those who did not receive regular physical activity (Table 3).

The final anxiety regression model explained $41.2 \%$ of the total variance; blocks $1,2,3$, and 4 individually explained $22.9 \%, 4.3 \%, 10.6 \%$, and $3.4 \%$, respectively. Male doctors presented with lower anxiety rates compared with female doctors $(\mathrm{OR}=0.410, p=0.052)$. The presence of a psychological/psychiatric history of illness $(\mathrm{OR}=8.188, p=0.017)$ was associated with higher anxiety rates. Regarding the work stressors perceived by physicians, relationship problems with other health professionals $(\mathrm{OR}=3.218, p=0.023)$ and excess work (OR $=2.396, p=0.074)$ were associated with more anxiety (Table 4).

\section{Discussion}

This study evaluated the prevalence of the distress conditions burnout, depression, and anxiety using evaluation instruments and cutoff points that have been widely used in previous studies. Approximately 58\%, 12\%, and $19 \%$ of physicians who treat patients with cancer show burnout, depression, and anxiety, respectively. In addition, we identified distress predictors among oncologists. Clearly, a considerable proportion of oncologists should be cared for in addition to caring for their patients. To the best of our knowledge, this is the first study to use hierarchical regression models in order to evaluate factors associated with distress conditions in oncologists. Of the factors evaluated, issues related to the perception of stressors at work explained burnout best; in turn, these same stressors had little importance with regard to anxiety and depression.

The mental health of physicians is a relevant topic. Previous studies conducted with physicians from distinct countries showed rates of depressive symptoms varying from 8.8 and $28.1 \%$ [20-25]. In a Chinese study [25], a 


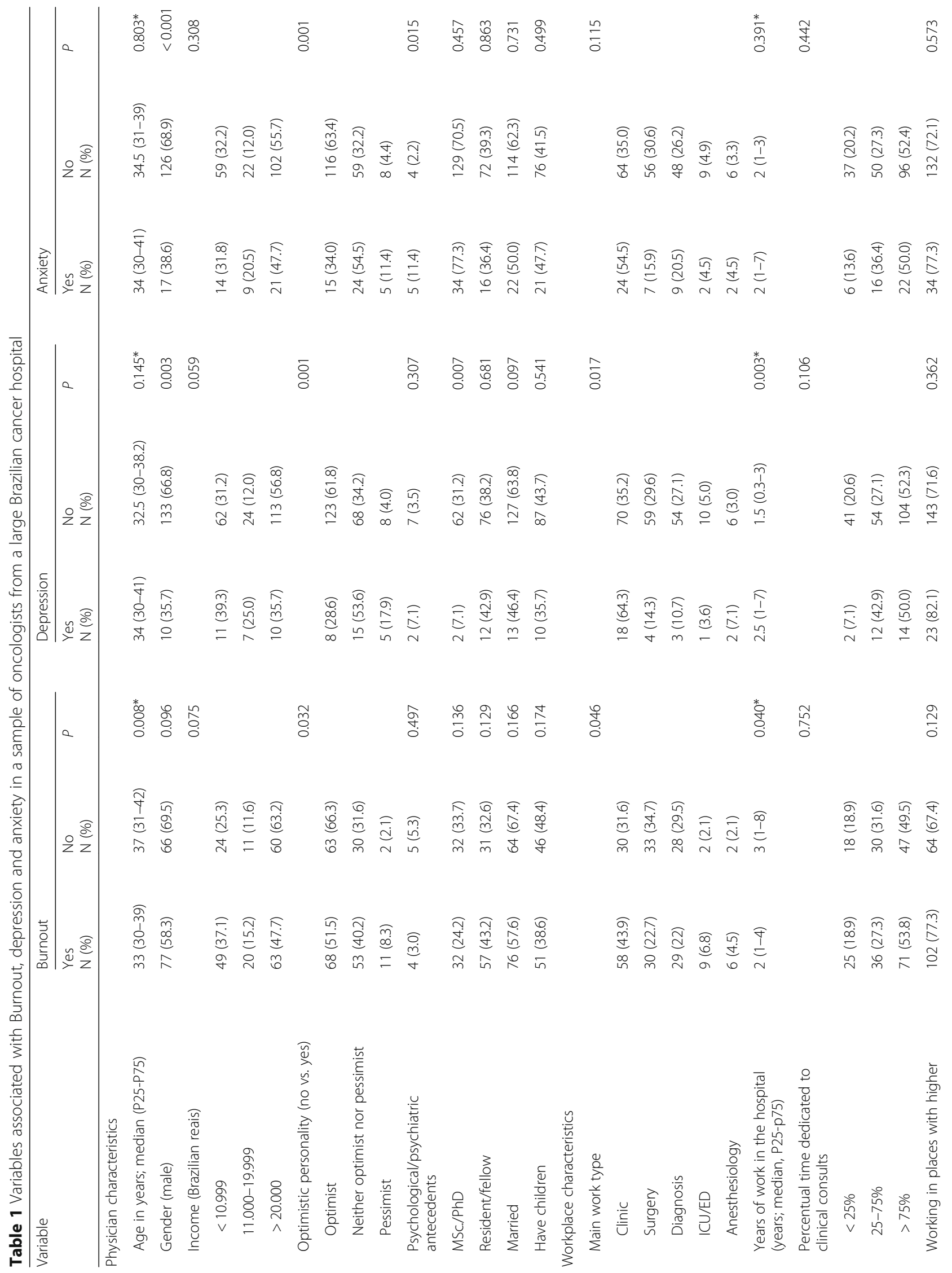




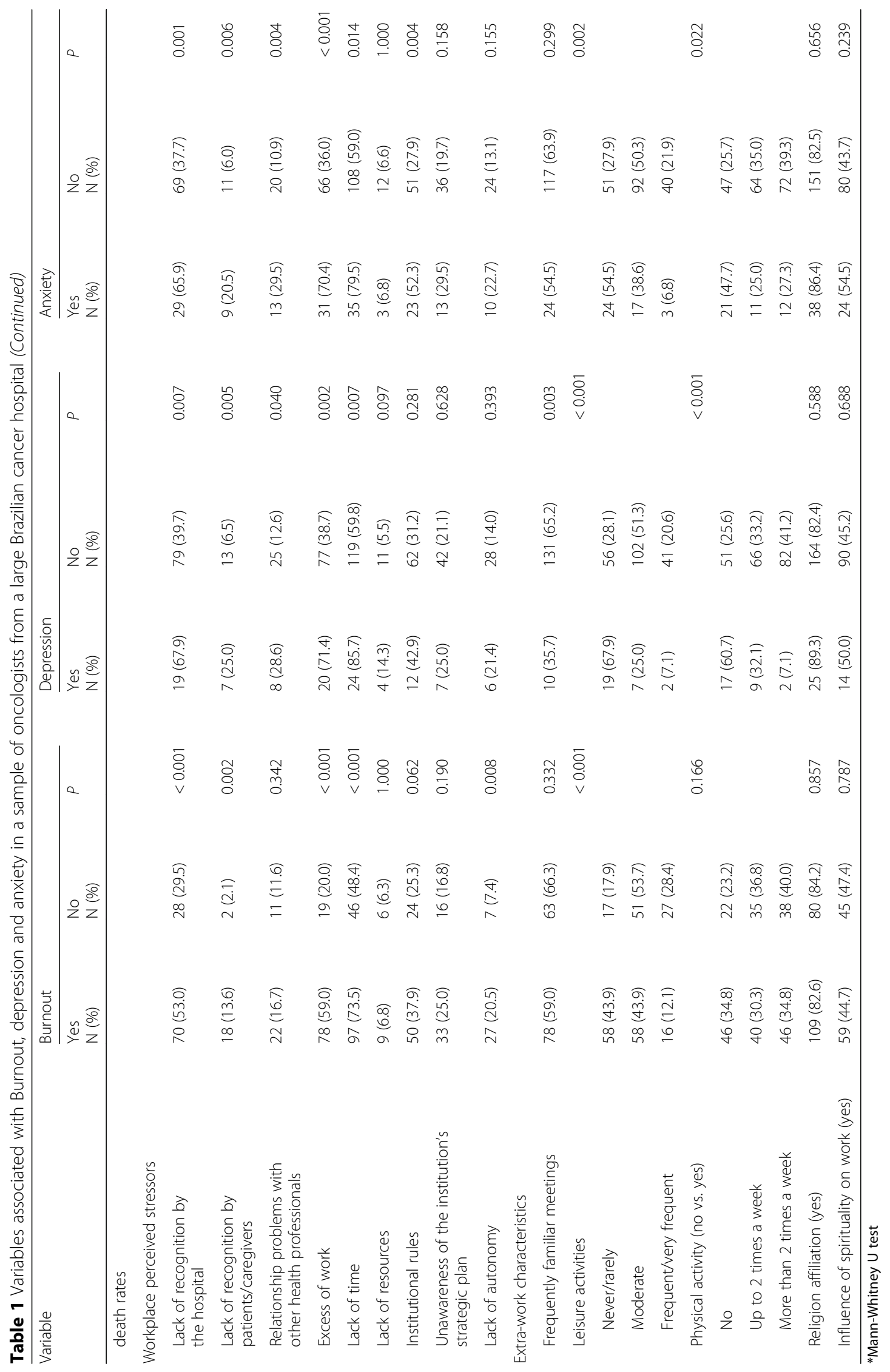


Table 2 Hierarchical binary logistic regression on potential variables associated with burnout in physicians from a cancer hospital

\begin{tabular}{|c|c|c|c|c|c|c|c|c|}
\hline \multirow[t]{2}{*}{ Variables } & \multicolumn{2}{|c|}{ Block $1^{\text {a }}$} & \multicolumn{2}{|c|}{ Block $2^{\text {a }}$} & \multicolumn{2}{|c|}{ Block $3^{a}$} & \multicolumn{2}{|c|}{ Block $4^{\text {a }}$} \\
\hline & OR & $p$-value & $\mathrm{OR}$ & $p$-value & $\mathrm{OR}$ & $p$-value & $\mathrm{OR}$ & $p$-value \\
\hline \multicolumn{9}{|l|}{ Block 1 - Physician characteristics } \\
\hline Age; years & 0.959 & 0.041 & 0.952 & 0.104 & 0.958 & 0.236 & 0.946 & 0.134 \\
\hline \multicolumn{9}{|l|}{ Optimistic personality } \\
\hline Optimist & 1.000 & & 1.000 & & 1.000 & & 1.000 & \\
\hline Neither optimist nor pessimist & 1.681 & 0.080 & 1.773 & 0.070 & 1.708 & 0.147 & 1.643 & 0.200 \\
\hline Pessimist & 5.160 & 0.044 & 5.348 & 0.051 & 6.400 & 0.052 & 7.601 & 0.036 \\
\hline Gender (male) & 0.729 & 0.290 & 0.857 & 0.663 & 1.196 & 0.637 & 1.418 & 0.380 \\
\hline \multicolumn{9}{|l|}{ Income (Brazilian reais) } \\
\hline$<10.999$ & 1.000 & & 1.000 & & 1.000 & & & \\
\hline 11.000-19.999 & 1.047 & 0.923 & 1.003 & 0.995 & 0.742 & 0.575 & 0.870 & 0.803 \\
\hline$>20.000$ & 0.877 & 0.737 & 0.711 & 0.417 & 0.399 & 0.063 & 0.492 & 0.168 \\
\hline \multicolumn{9}{|l|}{ Block 2 - Workplace characteristics } \\
\hline \multicolumn{9}{|l|}{ Main work type } \\
\hline Clinic & & & 1.000 & & 1.000 & & 1.000 & \\
\hline Surgery & & & 0.450 & 0.029 & 0.521 & 0.142 & 0.507 & 0.132 \\
\hline Diagnosis & & & 0.392 & 0.016 & 0.627 & 0.288 & 0.660 & 0.364 \\
\hline ICU/ED & & & 3.318 & 0.154 & 5.467 & 0.075 & 6.456 & 0.063 \\
\hline Anesthesiology & & & 1.760 & 0.594 & 0.834 & 0.853 & 0.672 & 0.688 \\
\hline Years of work in the hospital (continuous) & & & 0.998 & 0.966 & 1.002 & 0.966 & 1.011 & 0.808 \\
\hline \multicolumn{9}{|l|}{ Block 3 - Workplace perceived stressors } \\
\hline Lack of recognition by the hospital & & & & & 2.200 & 0.044 & 2.605 & 0.018 \\
\hline Lack of recognition by patients/caregivers & & & & & 4.333 & 0.081 & 4.780 & 0.074 \\
\hline Excess of work & & & & & 5.187 & $<0.001$ & 4.735 & $<0.001$ \\
\hline Lack of time & & & & & 1.697 & 0.133 & 1.420 & 0.339 \\
\hline Institutional rules & & & & & 0.967 & 0.932 & 0.824 & 0.627 \\
\hline Lack of autonomy & & & & & 2.216 & 0.141 & 2.249 & 0.148 \\
\hline \multicolumn{9}{|l|}{ Block 4 - Extra-work characteristics } \\
\hline \multicolumn{9}{|l|}{ Leisure activities } \\
\hline Never/rarely & & & & & & & 1.000 & \\
\hline Moderate & & & & & & & 0.321 & 0.009 \\
\hline Frequent/very frequent & & & & & & & 0.362 & 0.065 \\
\hline Model Chi-square & 18.511 & 0.005 & 32.719 & 0.001 & 81.397 & $<0.001$ & 88.866 & $<0.001$ \\
\hline Block Chi-square & 18.511 & 0.005 & 14.208 & 0.014 & 48.678 & $<0.001$ & 7.489 & 0.024 \\
\hline Nagelkerke's $R^{2}$ & 0.105 & & 0.181 & & 0.405 & & 0.436 & \\
\hline Change in Nagelkerke's $R^{2}$ & & & 0.076 & & 0.224 & & 0.031 & \\
\hline
\end{tabular}

${ }^{\mathrm{a}}$ In all blocks there were 132 events of burnout

sample of 2641 physicians showed a $25.6 \%$ prevalence of anxiety symptoms. The rates of anxiety and depression in the present study are compatible with those in the literature; however, if we had used cutoff points for mild symptoms, then we would have found rates greater than those in the literature (i.e., ranging from 30 to 40\%).

At least $50 \%$ of North American physicians have burnout [26, 27]. Among the various medical specialties, those who treat patients entering the health system (e.g., general practitioners and internists) have a higher incidence of burnout [26]. A recent meta-analysis showed that $32 \%$ of oncologists have high levels of burnout [4]. In our study, almost $60 \%$ of physicians were identified as having burnout; those who worked in intensive care or emergency medicine were most affected. We believe that working in sectors with potentially serious cases 
Table 3 Hierarchical binary logistic regression on potential variables associated with depression in physicians from a cancer hospital

\begin{tabular}{|c|c|c|c|c|c|c|c|c|}
\hline \multirow[t]{2}{*}{ Variables } & \multicolumn{2}{|l|}{ Block $1^{a}$} & \multicolumn{2}{|c|}{ Block $2^{\text {a }}$} & \multicolumn{2}{|c|}{ Block $3^{a}$} & \multicolumn{2}{|c|}{ Block $4^{\text {a }}$} \\
\hline & $\overline{\mathrm{OR}}$ & $\overline{p \text {-value }}$ & $\overline{\mathrm{OR}}$ & $\overline{p \text {-value }}$ & $\overline{\mathrm{OR}}$ & $\overline{p \text {-value }}$ & $\overline{\mathrm{OR}}$ & $\overline{p \text {-value }}$ \\
\hline \multicolumn{9}{|l|}{ Block 1 - Physician characteristics } \\
\hline Age in years & 0.970 & 0.425 & 1.020 & 0.714 & 1.032 & 0.600 & 0.944 & 0.515 \\
\hline \multicolumn{9}{|l|}{ Income (Brazilian reais) } \\
\hline$<10.999$ & 1.000 & & 1.000 & & 1.000 & & 1.000 & \\
\hline 11.000-19.999 & 2.263 & 0.176 & 2.447 & 0.184 & 3.500 & 0.106 & 10.729 & 0.021 \\
\hline$>20.000$ & 1.353 & 0.671 & 0.908 & 0.902 & 0.664 & 0.634 & 0.802 & 0.827 \\
\hline Gender (male vs. female) & 0.271 & 0.005 & 0.328 & 0.025 & 0.302 & 0.034 & 0.284 & 0.055 \\
\hline \multicolumn{9}{|l|}{ Optimistic personality } \\
\hline Optimist & 1.000 & & 1.000 & & 1.000 & & 1.000 & \\
\hline Neither optimist nor pessimist & 3.679 & 0.008 & 5.087 & 0.002 & 3.187 & 0.045 & 3.034 & 0.104 \\
\hline Pessimist & 10.188 & 0.002 & 14.180 & 0.001 & 13.309 & 0.005 & 18.440 & 0.008 \\
\hline MSc./PhD (yes vs. no) & 0.192 & 0.050 & 0.253 & 0.128 & 0.281 & 0.174 & 0.245 & 0.181 \\
\hline Married(yes vs. no) & 0.872 & 0.815 & 1.005 & 0.993 & 0.779 & 0.724 & 0.341 & 0.230 \\
\hline \multicolumn{9}{|l|}{ Block 2 - Workplace characteristics } \\
\hline \multicolumn{9}{|l|}{ Main work type } \\
\hline Clinic & & & 1.000 & & 1.000 & & 1.000 & \\
\hline Surgery & & & 0.253 & 0.049 & 0.368 & 0.192 & 0.126 & 0.029 \\
\hline Diagnosis & & & 0.119 & 0.004 & 0.210 & 0.061 & 0.206 & 0.096 \\
\hline ICU/ED & & & 0.371 & 0.411 & 0.247 & 0.329 & 0.500 & 0.698 \\
\hline Anesthesiology & & & 2.182 & 0.476 & 2.372 & 0.463 & 2.014 & 0.593 \\
\hline Years of work in the hospital (continuous) & & & 0.835 & 0.140 & 0.836 & 0.155 & 0.966 & 0.831 \\
\hline \multicolumn{9}{|l|}{ Block 3 - Workplace perceived stressors } \\
\hline Lack of recognition by the hospital & & & & & 2.139 & 0.260 & 2.932 & 0.181 \\
\hline Lack of recognition by patients/caregivers & & & & & 1.458 & 0.628 & 1.308 & 0.225 \\
\hline $\begin{array}{l}\text { Relationship problems with other } \\
\text { health professionals }\end{array}$ & & & & & 2.821 & 0.131 & 4.035 & 0.073 \\
\hline Excess of work & & & & & 1.337 & 0.647 & 1.146 & 0.855 \\
\hline Lack of time & & & & & 2.505 & 0.227 & 0.960 & 0.964 \\
\hline Lack of resources & & & & & 2.544 & 0.285 & 7.948 & 0.094 \\
\hline \multicolumn{9}{|l|}{ Block 4 - Extra-work characteristics } \\
\hline \multicolumn{9}{|l|}{ Leisure activities } \\
\hline Never/rarely & & & & & & & 1.000 & \\
\hline Moderate & & & & & & & 0.254 & 0.097 \\
\hline Frequent/very frequent & & & & & & & 0.707 & 0.773 \\
\hline \multicolumn{9}{|l|}{ Physical activity } \\
\hline No & & & & & & & 1.000 & \\
\hline Up to 2 times a week & & & & & & & 0.369 & 0.156 \\
\hline More than 2 times a week & & & & & & & 0.049 & 0.006 \\
\hline Frequently familiar meetings (yes vs. no) & & & & & & & 0.261 & 0.069 \\
\hline Model Chi-square & 32.286 & $<0.001$ & 49.566 & 0.001 & 61.374 & $<0.001$ & 83.322 & $<0.001$ \\
\hline Block Chi-square & 32.286 & $<0.001$ & 17.280 & 0.004 & 11.809 & 0.066 & 21.947 & 0.001 \\
\hline Nagelkerke's $R^{2}$ & 0.252 & & 0.373 & & 0.450 & & 0.584 & \\
\hline Change in Nagelkerke's $R^{2}$ & & & 0.121 & & 0.077 & & 0.134 & \\
\hline
\end{tabular}

a In all blocks there were 28 events of depression 
Table 4 Hierarchical binary logistic regression on potential variables associated with anxiety in physicians from a cancer hospital

\begin{tabular}{|c|c|c|c|c|c|c|c|c|}
\hline \multirow[t]{2}{*}{ Variables } & \multicolumn{2}{|l|}{ Block $1^{a}$} & \multicolumn{2}{|c|}{ Block $2^{\text {a }}$} & \multicolumn{2}{|c|}{ Block $3^{a}$} & \multicolumn{2}{|c|}{ Block $4^{\text {a }}$} \\
\hline & $\overline{\mathrm{OR}}$ & $\overline{p \text {-value }}$ & $\overline{\mathrm{OR}}$ & $\overline{p \text {-value }}$ & $\overline{\mathrm{OR}}$ & $\overline{p \text {-value }}$ & $\overline{\mathrm{OR}}$ & $\overline{p \text {-value }}$ \\
\hline \multicolumn{9}{|l|}{ Block 1 - Physician characteristics } \\
\hline Gender (male vs. female) & 0.235 & $<0.001$ & 0.261 & 0.001 & 0.326 & 0.012 & 0.410 & 0.052 \\
\hline Psychological/psychiatric antecedents & 11.041 & 0.002 & 10.205 & 0.003 & 7.519 & 0.018 & 8.188 & 0.017 \\
\hline \multicolumn{9}{|l|}{ Optimistic personality } \\
\hline Optimist & 1.000 & & 1.000 & & 1.000 & & 1.000 & \\
\hline Neither optimist nor pessimist & 3.121 & 0.003 & 3.808 & 0.001 & 2.680 & 0.023 & 2.406 & 0.049 \\
\hline Pessimist & 5.182 & 0.015 & 5.804 & 0.014 & 3.984 & 0.082 & 4.027 & 0.091 \\
\hline \multicolumn{9}{|l|}{ Block 2 - Workplace characteristics } \\
\hline \multicolumn{9}{|l|}{ Main work type } \\
\hline Clinic & & & 1.000 & & 1.000 & & 1.000 & \\
\hline Surgery & & & 0.433 & 0.126 & 0.632 & 0.434 & 0.556 & 0.326 \\
\hline Diagnosis & & & 0.459 & 0.107 & 0.892 & 0.835 & 1.056 & 0.911 \\
\hline ICU/ED & & & 0.518 & 0.472 & 0.525 & 0.520 & 0.530 & 0.533 \\
\hline Anesthesiology & & & 1.116 & 0.907 & 1.417 & 0.719 & 1.223 & 0.838 \\
\hline \multicolumn{9}{|l|}{ Block 3 - Workplace perceived stressors } \\
\hline Lack of recognition by the hospital & & & & & 1.554 & 0.366 & 1.603 & 0.350 \\
\hline Lack of recognition by patients/caregivers & & & & & 1.977 & 0.288 & 2.638 & 0.152 \\
\hline $\begin{array}{l}\text { Relationship problems with other } \\
\text { health professionals }\end{array}$ & & & & & 3.144 & 0.023 & 3.218 & 0.023 \\
\hline Excess of work & & & & & 2.405 & 0.060 & 2.396 & 0.074 \\
\hline Lack of time & & & & & 1.510 & 0.417 & 1.237 & 0.686 \\
\hline Institutional rules & & & & & 1.704 & 0.222 & 1.756 & 0.223 \\
\hline \multicolumn{9}{|l|}{ Block 4 - Extra-work characteristics } \\
\hline \multicolumn{9}{|l|}{ Leisure activities } \\
\hline Never/rarely & & & & & & & 1.000 & \\
\hline Moderate & & & & & & & 0.784 & 0.610 \\
\hline Frequent/very frequent & & & & & & & 0.317 & 0.164 \\
\hline \multicolumn{9}{|l|}{ Physical activity } \\
\hline No & & & & & & & 1.000 & \\
\hline Up to 2 times a week & & & & & & & 0.400 & 0.093 \\
\hline More than 2 times a week & & & & & & & 0.594 & 0.311 \\
\hline Model Chi-square & 35.093 & $<0.001$ & 42.442 & $<0.001$ & 61.332 & $<0.001$ & 67.654 & $<0.001$ \\
\hline Block Chi-square & 35.093 & $<0.001$ & 7.349 & 0.196 & 18.890 & 0.004 & 6.321 & 0.176 \\
\hline Nagelkerke's $R^{2}$ & 0.229 & & 0.272 & & 0.378 & & 0.412 & \\
\hline Change in Nagelkerke's $R^{2}$ & & & 0.043 & & 0.106 & & 0.034 & \\
\hline
\end{tabular}

Controlled for age and years of practice in the hospital

${ }^{a}$ In all blocks there were 44 events of anxiety

increases the risk of burnout. However, working in places with higher death rates was not associated with a higher prevalence of burnout. Thus, it is possible that caring for patients with cancer who have an indication for invasive measures, but not necessarily those with advanced cancer in palliative care (without an indication of invasive measures), predicts the development of burnout. The rates of depression and anxiety in our study are consistent with a recent meta-analysis, which showed that $27 \%$ of oncologists have psychiatric comorbidities, and at least $12 \%$ test positive for depression.

Burnout is recognized as a work-related problem, and the organizational environment plays a critical role in its development [28]. Physicians' perceptions of their 
supervisors' leadership qualities are correlated with burnout and job satisfaction [29]. However, the association between anxiety, depression, and occupational aspects is less obvious. In fact, we observed that physicians' perceptions of their stressors at work explained only about $5 \%$ and $10 \%$ of the total variance of depression and anxiety, respectively. Promoting advancement in one's professional career, guidance, and recognition of the results obtained are some of the strategies employed to reduce burnout rates among physicians [30]. Caruso et al. identified lack of recognition as a significant organizational stressors in a cancer hospital in Italy [31]. Similar results were obtained among medical ophthalmologists [32] and anesthesiologists [33]. Workload, time pressure, pressure for efficiency, role conflicts, lack of control over work, lack of support from supervisors and co-workers, little participation in decision making, lack of autonomy, and challenges with the work-life balance are common work-related factors associated with burnout $[16,28]$.

This study has limitations. The first is that it is a cross-sectional study, and it is impossible to determine cause-and-effect relationships. The second is that we evaluated work stressors based on the opinions of physicians and did not objectively measure their number of appointments or actual working time. However, we believe that perceptions of one's work, and not necessarily the work itself, are most important with regard to the genesis of burnout. Another limitation is that we did not evaluate the number of deaths that each physician witnessed in his or her daily life; rather, we arbitrarily divided the workplaces into those with greater or fewer deaths.

Screening for emotional distress among physicians who treat patients with cancer is currently mandatory [28]. In particular, burnout cannot be considered a problem only for the doctor; rather, it is a shared responsibility with the hospital. Individual-focused treatment strategies (e.g., stress management and self-care training, communication skills training, and mindfulness-based approaches) or workplace or organizational changes (e.g., briefer attending rotation lengths, various modifications to clinical work processes, and practice delivery changes) are effective. However, one must define the most effective strategies for specific populations [34]. Healthcare managers must recognize that the well-being of their workers is an essential goal, as are the satisfaction and improvement of the health of their patients, without disregarding the costs involved. Physicians must be mentally prepared for proper engagement and production.

\section{Conclusions}

In summary, approximately $12 \%, 22 \%$, and $60 \%$ of oncologists experience depression, anxiety, and burnout. Work-related stressors are associated with burnout, but few are associated with anxiety or depression. Outsideof-work characteristics explain little of the distress reported by physicians. Strategies focused on the perception of professional recognition and lowered workloads (which stimulate positive relationships between doctors and other health professionals) are desirable.

\section{Additional files}

Additional file 1: Figure S1. Conceptual model representing possible physician's distress-related categories. A: physician characteristics; B: Workplace characteristics; C: Workplace perceived stressors; D: Extra-work characteristics. (TIF $15367 \mathrm{~kb}$ )

Additional file 2: Questionnaire used in the present study. (DOC $44 \mathrm{~kb}$ )

Additional file 3: Figure S2. CONSORT flow diagram. (TIF 24 kb)

Additional file 4: Table S1. Demographic characteristics of the physicians. Table S2. Analysis of burnout in function of years of practice in the present hospital. (DOC $70 \mathrm{~kb}$ )

\section{Abbreviations}

BCH: Barretos Cancer Hospital; DP: depersonalization; ED: emergency department; EE: emotional exhaustion; HADS: Hospital Anxiety and Depression Scale; ICF: informed consent form; ICU: Intensive Care Unit; MBI: Maslach Burnout Inventory; PF: personal fulfillment; SD: standard deviation

\section{Acknowledgements}

The authors would like to thank all the physicians that accepted to participate in the present study. Additionally, the authors would like to thank Marco Antonio de Oliveira (statistician) from the Center for Research Support, Cancer Hospital of Barretos who helped in the statistical analyses.

\section{Funding}

This study was funded by Conselho Nacional de Desenvolvimento Científico e Tecnológico (CNPq, Proc. No 100184/2015-4). The funder had no role in study design, data collection and analysis, decision to publish, or preparation of the manuscript.

Availability of data and materials

All the data supporting our findings are included in this published article and its supplementary information files.

\section{Authors' contributions}

CEP and BSRP conceptualized the study. CEP, BPM and BSRP obtained the data. CEP and BSRP analyzed the data. All authors provided input on the

interpretation and they read and approved of the final draft of the manuscript.

Ethics approval and consent to participate

The Research Ethics Committee of HCB approved the study protocol (CEP/HCB no. 1.091.484/2015). Participants indicated their agreement to participate in the study via the electronic informed consent included in the survey form.

\section{Consent for publication}

Not applicable.

\section{Competing interests}

All authors declare that they have no competing interests.

\section{Publisher's Note}

Springer Nature remains neutral with regard to jurisdictional claims in published maps and institutional affiliations.

\section{Author details}

${ }^{1}$ Department of Clinical Oncology, Barretos Cancer Hospital, Barretos, São Paulo, Brazil. ' $H$ Health-Related Quality of Life Research Group (GPQual), Learning and Research Institute, Barretos Cancer Hospital, Barretos, São 
Paulo, Brazil. ${ }^{3}$ Barretos School of Health Sciences, Dr. Paulo Prata - FACISB, Barretos, São Paulo, Brazil. ${ }^{4}$ Departamento de Oncologia Clínica, Divisão de Mama e Ginecologia, Rua Antenor Duarte Vilella, 1331, Bairro Dr Paulo Prata, Barretos, SP CEP: 14784-400, Brazil.

\section{Received: 2 November 2017 Accepted: 16 October 2018}

Published online: 26 October 2018

\section{References}

1. CDC. Leading causes of death Centers for Disease Control Prevention. 2017. https://www.cdc.gov/nchs/fastats/leading-causes-of-death.htm. Accessed 14 May 2017.

2. McPhail S, Johnson S, Greenberg D, Peake M, Rous B. Stage at diagnosis and early mortality from cancer in England. Br J Cancer. 2015;112:S108-15.

3. Carneseca EC, Mauad EC, de AMAA, Dalbó RM, Longatto Filho A, Vazquez V de L. The hospital de Câncer de Barretos registry: an analysis of cancer survival at a single institution in Brazil over a 10-year period. BMC Res Notes. 2013;6:141.

4. Medisauskaite A, Kamau C. Prevalence of oncologists in distress: systematic review and meta-analysis. Psychooncology. 2017. https://doi.org/10.1002/ pon.4382.

5. Hlubocky FJ, Back AL, Shanafelt TD. Addressing burnout in oncology: why Cancer care clinicians are at risk, what individuals can do, and how organizations can respond. Am Soc Clin Oncol Educ Book. 2016;35:271-9.

6. Dyrbye LN, Harper W, Durning SJ, Moutier C, Thomas MR, Massie FS, et al. Patterns of distress in US medical students. Med Teach. 2011;33:834-9.

7. Dewa CS, Loong D, Bonato S, Thanh NX, Jacobs P. How does burnout affect physician productivity? A systematic literature review. BMC Health Serv Res. 2014;14:325.

8. Guille C, Clark S, Amstadter AB, Sen S. Trajectories of depressive symptoms in response to prolonged stress in medical interns. Acta Psychiatr Scand. 2014;129:109-15.

9. Oppong Asante K, Andoh-Arthur J. Prevalence and determinants of depressive symptoms among university students in Ghana. J Affect Disord. 2015;171:161-6.

10. Goebert D, Thompson D, Takeshita J, Beach C, Bryson P, Ephgrave K, et al. Depressive symptoms in medical students and residents: a multischool study. Acad Med. 2009;84:236-41.

11. Shanafelt TD, Sloan JA, Habermann TM. The well-being of physicians. Am J Med. 2003;114:513-9.

12. Whippen DA, Canellos GP. Burnout syndrome in the practice of oncology: results of a random survey of 1,000 oncologists. J Clin Oncol. 1991;9:1916-20.

13. Glasberg J, Horiuti L, Novais MAB, Canavezzi AZ, da Costa Miranda V, Chicoli FA, et al. Prevalence of the burnout syndrome among Brazilian medical oncologists. Rev Assoc Med Bras. 2007;53:85-9.

14. Lwanga SK, Lemeshow S. Sample size determination in health studies:a practical manual. Geneva: World Health Organization; 1991.

15. Maslach C, Jackson S. The measurement of experienced burnout. J Occup Behav. 1981;2:99-113.

16. Maslach C, Schaufeli WB, Leiter MP. Job burnout. Annu Rev Psychol. 2001;52: 397-422.

17. Cubero DIG, Fumis RRL, de Sá TH, Dettino A, Costa FO, Van Eyll BMRHA, et al. Burnout in medical oncology fellows: a prospective multicenter cohort study in Brazilian institutions. J Cancer Educ. 2016;31:582-7.

18. Botega NJ, Bio MR, Zomignani MA, Garcia C, Pereira WA. Mood disorders among inpatients in ambulatory and validation of the anxiety and depression scale HAD. Rev Saude Publica. 1995;29:355-63.

19. Nagelkerke N. A note on a general definition of the coefficient of determination. Biometrika. 1991;78:691-2.

20. Coomber S, Todd C, Park G, Baxter P, Firth-Cozens J, Shore S. Stress in UK intensive care unit doctors. Br J Anaesth. 2002;89:873-81.

21. Lloyd S, Streiner D, Shannon S. Burnout, depression, life and job satisfaction among Canadian emergency physicians. J Emerg Med. 1994;12:559-65.

22. Schwenk TL, Gorenflo DW, Leja LM. A survey on the impact of being depressed on the professional status and mental health care of physicians. J Clin Psychiatry. 2008;69:617-20.

23. Vaglum P, Falkum E. Self-criticism, dependency and depressive symptoms in a nationwide sample of Norwegian physicians. J Affect Disord. 1999;52:153-9.

24. Wada K, Yoshikawa T, Goto T, Hirai A, Matsushima E, Nakashima Y, et al. Association of depression and suicidal ideation with unreasonable patient demands and complaints among Japanese physicians: a national crosssectional survey. Int J Behav Med. 2011;18:384-90.

25. Gong Y, Han T, Chen W, Dib HH, Yang G, Zhuang R, et al. Prevalence of anxiety and depressive symptoms and related risk factors among physicians in China: a cross-sectional study. Harper DM, editor. PLoS One. 2014;9:e103242.

26. Shanafelt TD, Boone S, Tan L, Dyrbye LN, Sotile W, Satele D, et al. Burnout and satisfaction with work-life balance among US physicians relative to the general US population. Arch Intern Med. 2012;172:1377.

27. Shanafelt TD, Hasan O, Dyrbye LN, Sinsky C, Satele D, Sloan J, et al. Changes in burnout and satisfaction with work-life balance in physicians and the general US working population between 2011 and 2014. Mayo Clin Proc. 2015;90:1600-13.

28. Shanafelt TD, Noseworthy JH. Executive leadership and physician wellbeing: Nine Organizational Strategies to Promote Engagement and Reduce Burnout. Mayo Clin Proc. 2017;92:129-46.

29. Shanafelt TD, Gorringe G, Menaker R, Storz KA, Reeves D, Buskirk SJ, et al. Impact of organizational leadership on physician burnout and satisfaction. Mayo Clin Proc. 2015;90:432-40.

30. Sigsbee B, Bernat JL. Physician burnout: a neurologic crisis. Neurology. 2014; 83:2302-6.

31. Caruso A, Vigna C, Bigazzi V, Sperduti I, Bongiorno L, Allocca A. Burnout among physicians and nurses working in oncology. Med Lav. 2012;103:96-105.

32. Viviers S, Lachance L, Maranda M-F, Ménard C. Burnout, psychological distress, and overwork: the case of Quebec's ophthalmologists. Can J Ophthalmol. 2008;43:535-46.

33. Rama-Maceiras $P$, Parente $S$, Kranke $P$. Job satisfaction, stress and burnout in anaesthesia: relevant topics for anaesthesiologists and healthcare managers? Eur J Anaesthesiol. 2012;29:311-9.

34. West CP, Dyrbye LN, Erwin PJ, Shanafelt TD. Interventions to prevent and reduce physician burnout: a systematic review and meta-analysis. Lancet. 2016;388:2272-81.

\section{Ready to submit your research? Choose BMC and benefit from:}

- fast, convenient online submission

- thorough peer review by experienced researchers in your field

- rapid publication on acceptance

- support for research data, including large and complex data types

- gold Open Access which fosters wider collaboration and increased citations

- maximum visibility for your research: over $100 \mathrm{M}$ website views per year

At BMC, research is always in progress.

Learn more biomedcentral.com/submissions 